\title{
Early inter-hospital transfer of patients with myocardial infarction without a doctor, paramedic or nurse on board: results from a French regional emergency care network
}

Sebastien Cassan ${ }^{1 \dagger}$, Mihaela Rata ${ }^{2 \dagger}$, Claire Vallenet ${ }^{1}$, Philippe Fromage ${ }^{1}$, Frederic Champly ${ }^{3}$, Patrick Broin ${ }^{3}$, Guillaume Peribois ${ }^{4}$, Valerie Sierra ${ }^{4}$, Cedric Lutz ${ }^{2}$, Lionel Mangin ${ }^{2}$, Dominique Savary ${ }^{2}$, François-Xavier Ageron ${ }^{2}$, and Loic Belle $2^{2^{*}}$ for the SCA-Alp Investigators ${ }^{\dagger}$

\begin{abstract}
Background: In France, patients with acute coronary syndromes (ACS) are usually transferred from remote hospitals to percutaneous coronary intervention (PCI) centres in mobile intensive care units (MICUs) with on-board medical staff. They are then returned to the remote hospitals by MICU $48 \mathrm{~h}$ after PCI. However, MICU transportation and beds in a PCl centre are in short supply. Therefore, we investigated clinical outcomes among intermediate-risk ACS patients who were transferred in private ambulances without an on-board medic or paramedic; and returned to the remote hospital sooner after $\mathrm{PCl}$.

Methods: In the French Alps, the RESURCOR network manages 'SCA-Alp' transfers using strict management protocols in ambulances with trained drivers and automatic external defibrillators, but without heart rhythm monitoring. We conducted an observational retrospective study that assessed outcomes (death and emergency return to the $\mathrm{PCl}$ centre within $48 \mathrm{~h}$ ) in patients transferred using SCA-Alp. Our population comprised stabilized patients with ST-segment elevation myocardial infarction (STEMI) who returned to the remote hospital within 24-48 h of PCl, and uncomplicated patients with non-ST-segment elevation myocardial infarction (NSTEMI) within 24-72 h of symptom onset who come from and returned to ('round-trip') the remote hospital on the day of $\mathrm{PCl}$ (return $<12 \mathrm{~h}$ after PCl).

Results: Between 2010 and 2014, 101 STEMI and 490 NSTEMI patients were transferred using SCA-Alp. No adverse events occurred during transportation and no deaths were reported. Two of 591 patients (0.3\% [95\% confidence interval $0.1-1.4 \%]$ ) experienced a stent thrombosis within $48 \mathrm{~h}$ of $\mathrm{PCl}$ that required a second urgent $\mathrm{PCl}$; both were event free at 6-month follow-up.
\end{abstract}

Conclusions: Inter-hospital transfer using SCA-Alp is associated with low event rates in intermediate-risk ACS patients, allowing a more streamlined use of medical facilities and freeing-up of beds in $\mathrm{PCl}$ centres.

Keywords: SCA-Alp protocol, Myocardial infarction, Percutaneous coronary intervention, Transfer, France

\footnotetext{
* Correspondence: loic.belle@wanadoo.fr

† Sebastien Cassan and Mihaela Rata contributed equally to this work.

The collaborative authors for the SCA-Alp Investigators are listed in the

Appendix.

${ }^{2}$ Department of Cardiology and Emergency Department, Centre Hospitalier

Annecy-Genevois, Annecy, France

Full list of author information is available at the end of the article
}

(c) The Author(s). 2019 Open Access This article is distributed under the terms of the Creative Commons Attribution 4.0 International License (http://creativecommons.org/licenses/by/4.0/), which permits unrestricted use, distribution, and reproduction in any medium, provided you give appropriate credit to the original author(s) and the source, provide a link to the Creative Commons license, and indicate if changes were made. The Creative Commons Public Domain Dedication waiver (http://creativecommons.org/publicdomain/zero/1.0/) applies to the data made available in this article, unless otherwise stated. 


\section{Background}

Urgent percutaneous coronary intervention (PCI) for ST-segment elevation myocardial infarction (STEMI) and early revascularization for non-ST-segment elevation myocardial infarction (NSTEMI) are recommended in international guidelines $[1,2]$. The main factors limiting the implementation of these recommendations are the geographic availability and the capacity of centres with cath-labs (PCI centres). One solution would be to shorten the stay of patients in PCI centres (i.e. transfer them between remote hospitals without cath-labs and $\mathrm{PCI}$ centres before/after the invasive procedure).

In France, following acute treatment, patients with STEMI remain in the PCI centre for $48 \mathrm{~h}$ before transfer. Patients with acute NSTEMI are transferred between hospitals in mobile intensive care units (MICUs), which have on-board medical/paramedic teams [3]. As both groups of patients are generally considered to be at high risk during this period, they require transfer with a doctor and nurse on board. Paul et al. [4] reported a high incidence of complications during the transportation of high-risk patients (i.e. within $12 \mathrm{~h}$ of acute STEMI and $24 \mathrm{~h}$ of complicated NSTEMI), justifying transportation with doctors on board, whereas Bawejski et al. [5] reported a low incidence of complications during the transportation of patients within $24 \mathrm{~h}$ of uncomplicated NSTEMI. Therefore, it may be possible to reassess the patients' individual risk levels and adapt the type of transfer (i.e. with or without medical/ paramedical staff) accordingly.

Four studies have reported on the safety of early transfer of patients with acute coronary syndromes (ACS) between remote hospitals and PCI centres [6-9]. These transfers were, however, conducted with doctors $[6,7]$ or nurses [8] on board and often involved low-risk patients (i.e. with unstable angina) or excluded high-risk patients with STEMI $[8,9]$. The safety of return transfers of STEMI patients to remote hospitals within $48 \mathrm{~h}$ of their admission to the PCI centre, and the early round-trip for patients with NSTEMI within $72 \mathrm{~h}$ of their admission to a remote hospital, without doctors or nurses on board, remains questionable.

In our region of France, intermediate-risk ACS patients can be transferred from a remote hospital to the PCI centre (NSTEMI patients only) and back to the remote centre after PCI (NSTEMI and STEMI patients) using the 'SCA-Alp' protocol. This involves an ambulance equipped with an automatic external defibrillator, driven by a driver with specialist training in basic life support, but without a medic or paramedic on board. Further, patients are returned to the remote hospital within $12 \mathrm{~h}$ (NSTEMI) or 24-48 h (STEMI) of PCI, rather than the standard $48 \mathrm{~h}$. The aim of this retrospective, observational study was to report clinical outcomes in such patients transferred using the SCA-Alp protocol.

\section{Methods}

This was a retrospective, observational study on early transfer (without doctors or nurses on board) of intermediate-risk patients with NSTEMI or STEMI between one of seven remote hospitals in the Haute-Savoie department in France and one PCI centre.

The Haute-Savoie department is a mountainous area with approximately 800,000 inhabitants in 2015 [10]. One PCI centre (Annecy hospital) collaborates with four remote hospitals that have intensive care units (ICUs) and a MICU team and three hospitals/clinics without ICUs or a MICU team (Fig. 1). Two remote hospitals with ICUs and MICU teams (Chambéry and Albertville), located outside the Haute-Savoie department, collaborate partially with the PCI centre. The PCI centre has two cath-labs and four on-call interventional cardiologists. Eight beds are available exclusively for pre- and post-coronary intervention monitoring in a room located close to the cath-lab from 8 am to $8 \mathrm{pm}$.

In this geographic area, the RESeau des URgences CORonaires (RESURCOR) network is a coordinated regional system of care for patients with cardiac emergencies, and forms part of REseau Nord Alpin des Urgences (RENAU). The RESURCOR network disseminates protocols via pocket cards and booklets, available at a dedicated website (www.renau.org). An ongoing regional prospective registry of STEMI patients has provided data since 2002 on the acute phase of patient care [11-15].

One of the protocols of the RESURCOR network - the SCA-Alp protocol (Fig. 2) - is used to implement early transfers from remote hospitals to and from the PCI centre for intermediate-risk patients with acute NSTEMI; and early return transfers from PCI centres to remote hospitals for intermediate-risk patients with acute STEMI. SCA-Alp transfers occur in private ambulances with two basic life support-trained drivers on board and equipped with an automatic defibrillator, but without heart rhythm monitoring. Prior to the introduction of the SCA-Alp protocol, high- and intermediate-risk patients would have been transferred by MICU, with low-risk patients being transported by regular ambulance; and patients would have remained in the PCI centre for $48 \mathrm{~h}$ after PCI.

Patients with NSTEMI who have been admitted to an ICU in a remote hospital are transferred according to the SCA-Alp protocol to the PCI centre within 24-72 $\mathrm{h}$ (Fig. 2; Table 1). Patients are only eligible for SCA-Alp transfer (instead of by MICU) from the remote hospital to the PCI centre if they had been stable for at least $24 \mathrm{~h}$ in the remote centre (i.e. no acute cardiac failure condition, no underlying ventricular arrhythmia, and no ST-segment depression $>3 \mathrm{~mm}$ in $\geq 2$ leads). Patients who underwent PCI were only eligible for SCA-Alp 


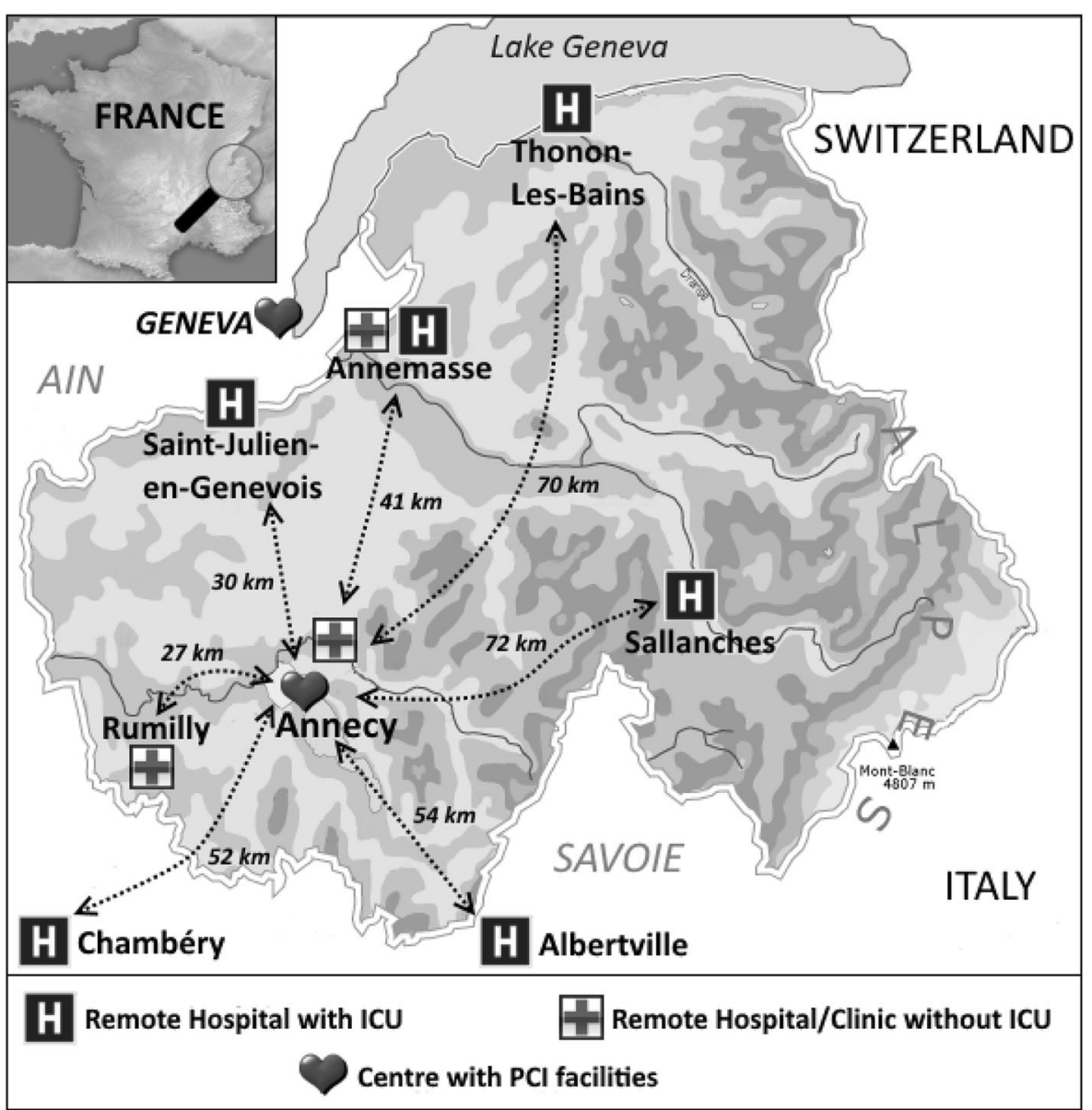

Fig. 1 The Haute-Savoie hospital network. ICU, intensive care unit; $\mathrm{PCl}$, percutaneous coronary intervention

transfer back to the remote centre within $12 \mathrm{~h}$ of the procedure if the PCI result was optimal. Otherwise, they remained in the PCI centre.

Patients with STEMI diagnosed in a remote hospital are transferred straight to the PCI centre in a MICU, where a primary or rescue angioplasty after thrombolysis may be performed (Fig. 2; Table 1). After PCI, intermediate-risk patients are transferred back to the remote hospital (closest to the patient's home) within 24-48 h using a SCA-Alp transfer. This only applies to patients with an optimal revascularization procedure and no recurrence of angina, acute cardiac failure, or significant ventricular arrhythmias in the $24 \mathrm{~h}$ following admission. High-risk STEMI patients (i.e. non-optimal revascularization, recurrence of angina, acute cardiac failure, or significant ventricular arrhythmias within 24 $\mathrm{h}$ after PCI) remain at the PCI centre.

Low-risk patients who are returned to the remote hospital $>48 \mathrm{~h}$ after PCI are not eligible for the SCA-Alp protocol. Instead, they are discharged or transferred back to the remote hospital by regular ambulance.

\section{Study population}

The population comprised consecutive patients admitted to the PCI centre in Annecy from January 2010 to December 2014 with an initial diagnosis of acute STEMI or NSTEMI. Patients with STEMI were eligible for inclusion if they had a transfer according to the SCA-Alp protocol to a remote hospital 24-48 $\mathrm{h}$ after admission to the PCI centre in Annecy. Patients with NSTEMI were eligible for inclusion if they were admitted to a remote hospital, transferred using the SCA-Alp protocol to the PCI centre in Annecy within $72 \mathrm{~h}$, and transferred back under the same protocol within $12 \mathrm{~h}$ of admission to the PCI centre in Annecy.

\section{Data collected and study endpoints}

Descriptive data were derived from the RESURCOR STEMI registry and the cath-lab database. Troponin concentrations were obtained from the remote hospital lab databases. In-hospital mortality data were derived from each hospital's database; retransfer from a remote 


\section{NSTEMI}

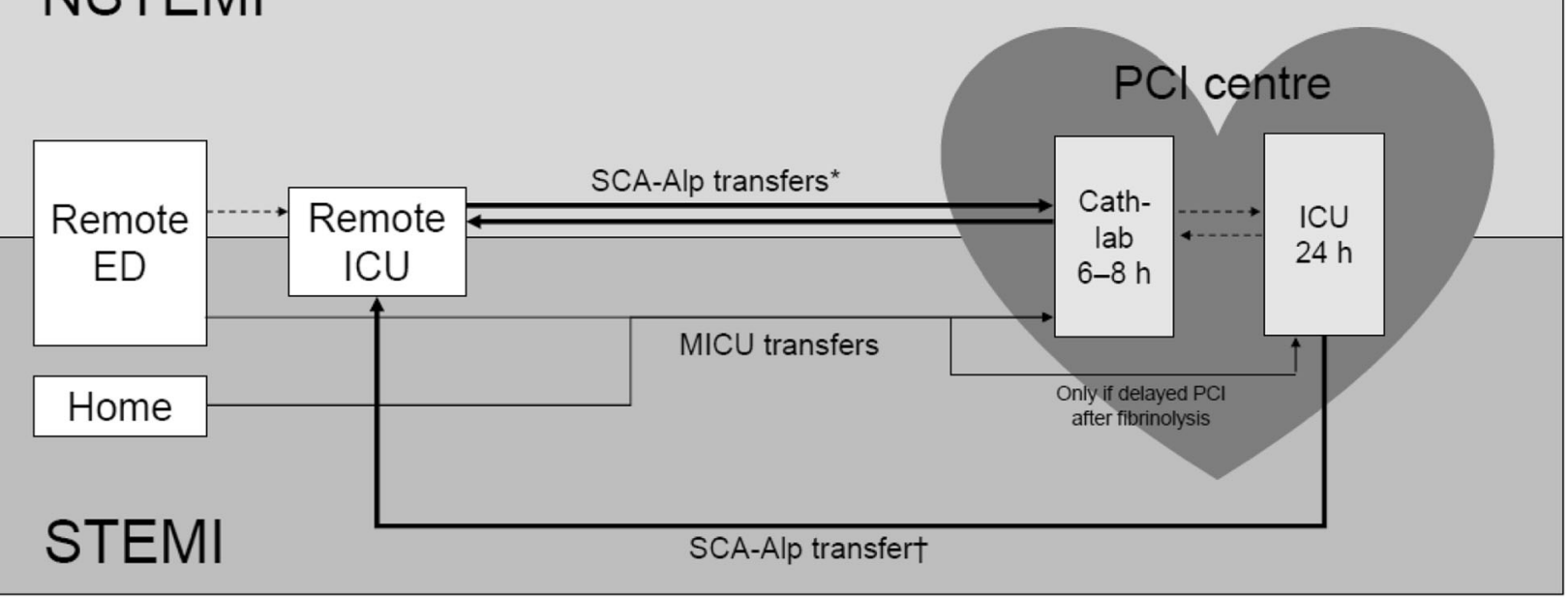

Fig. 2 Organization of transfers between remote hospitals and the PCI centre. ED: emergency department; ICU: intensive care unit; MICU: mobile intensive care unit; NSTEMI: non-ST-segment elevation myocardial infarction; PCl: percutaneous coronary intervention; STEMI: ST-segment elevation myocardial infarction. ${ }^{*}$ Only NSTEMI patients who had been stable for $\geq 24 \mathrm{~h}$ in the remote centre were eligible for SCA-Alp transfer to the $\mathrm{PCl}$ centre; only NSTEMI patients with optimal PCI results were eligible for SCA-Alp transfer back to the remote hospital (within $12 \mathrm{~h}$ of PCI). tOnly STEMI patients with an optimal revascularization procedure and no recurrence of angina, acute cardiac failure, or significant ventricular arrhythmias in the $24 \mathrm{~h}$ following admission were eligible for SCA-Alp transfer back to the remote hospital (24-48 $\mathrm{h}$ after PCl)

hospital to the PCI hospital for a coronary angiogram within $48 \mathrm{~h}$ of the return to the remote hospital was derived from the cath-lab database. The medical records (from the PCI centre and the remote hospitals) of all patients who underwent PCI were routinely examined by a study technician in charge of the cath-lab database and data on endpoints were collected.

The aim of this study was to determine the rate of adverse events associated with the SCA-Alp approach, to ascertain whether this approach is safe. The primary endpoints of this study were death within $48 \mathrm{~h}$ of return to the remote hospital (including during transfer) and the requirement for retransfer back to the PCI centre within $48 \mathrm{~h}$ for a coronary angiogram. Secondary endpoints were in-hospital stroke,
Thrombolysis In Myocardial Infarction (TIMI) major bleeding, major haematoma at the puncture site (defined as the need for a transfused haemostatic agent or surgical intervention), and intrastent thrombosis (or reocclusion of the dilated lesion) $>48 \mathrm{~h}$ after PCI. These endpoints were only available for patients who underwent PCI.

\section{Statistical analysis}

Values are expressed as mean \pm standard deviation (SD) for continuous variables and as counts and percentages for categorical variables. The $95 \%$ confidence interval for the primary outcome was calculated using the Wilson method. All analyses were conducted in Microsoft Excel.

Table 1 Recommended transfer types

\begin{tabular}{|c|c|c|c|}
\hline & Low-risk patients & Intermediate-risk patients & High-risk patients \\
\hline \multicolumn{4}{|l|}{ NSTEMI } \\
\hline $\begin{array}{l}\text { Remote hospital to } \mathrm{PCl} \\
\text { centre }\end{array}$ & $\begin{array}{l}\text { Ambulance if uncomplicated; }{ }_{;}^{\mathrm{a}}>72 \mathrm{~h} \\
\text { after admission }\end{array}$ & $\begin{array}{l}\text { SCA-Alp if uncomplicated; }{ }^{a} 24-72 \mathrm{~h} \\
\text { after admission }\end{array}$ & $\begin{array}{l}\text { MICU if uncomplicated; }{ }^{\mathrm{a}}<24 \mathrm{~h} \\
\text { after admission; or complicated }\end{array}$ \\
\hline Return to remote hospital & $\begin{array}{l}\text { Ambulance if uncomplicated; }{ }^{\mathrm{a}}>12 \mathrm{~h} \\
\text { after successful PCl }\end{array}$ & $\begin{array}{l}\text { SCA-Alp if uncomplicated; }{ }^{a}<12 \mathrm{~h} \\
\text { after successful PCl }\end{array}$ & \\
\hline \multicolumn{4}{|l|}{ STEMI } \\
\hline $\begin{array}{l}\text { Remote hospital (or home) } \\
\text { to } \mathrm{PCl} \text { centre }\end{array}$ & $\mathrm{MICU}$ & $\mathrm{MICU}$ & $\mathrm{MICU}$ \\
\hline Return to remote hospital & $\begin{array}{l}\text { Ambulance if uncomplicated }{ }^{\mathrm{b}}>48 \mathrm{~h} \\
\text { after PCl }\end{array}$ & $\begin{array}{l}\text { SCA-Alp if uncomplicated; } 24-48 \text { h } \\
\text { after successful PCl }\end{array}$ & $\begin{array}{l}\text { Remain in } \mathrm{PCl} \text { centre if complicated } \\
\text { or }<24 \mathrm{~h}\end{array}$ \\
\hline
\end{tabular}

MICU mobile intensive care unit, NSTEMI non-ST-segment elevation myocardial infarction, $P C I$ percutaneous coronary intervention, SCA-Alp ambulance with trained drivers and an automatic defibrillator, STEMI ST-segment elevation myocardial infarction

${ }^{a}$ No acute cardiac failure condition, no underlying ventricular arrhythmia, and no ST-segment depression $>3 \mathrm{~mm}$ in $\geq 2$ leads

${ }^{b}$ No cardiac failure, no recurrent angina, no significant ventricular arrhythmia 
A. STEMI

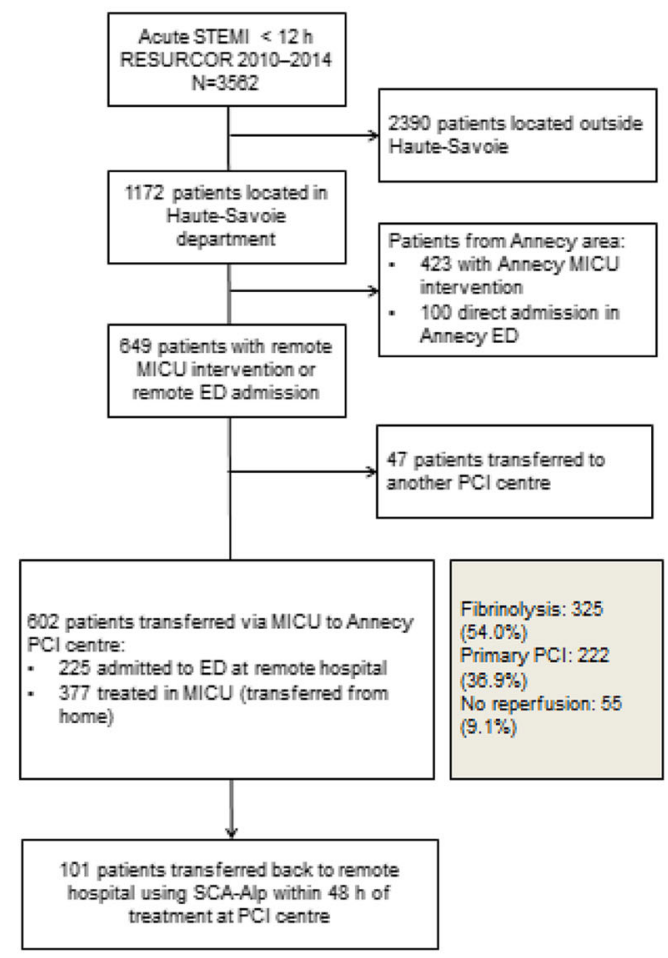

\section{B. NSTEM}

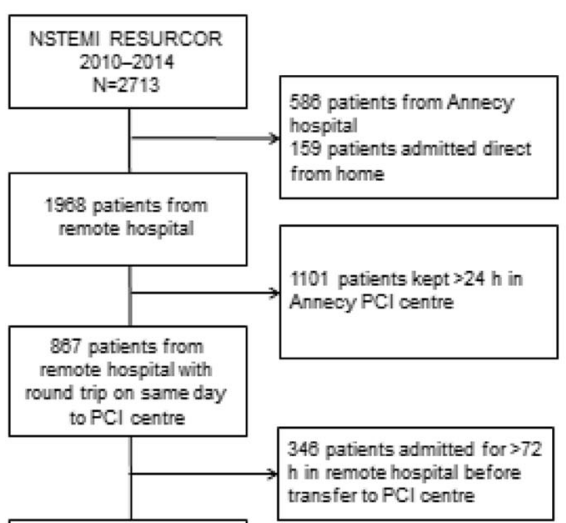
$h$ in remote hospital before transfer to $\mathrm{PCl}$ centre 521 patients from
remote hospital admitted
$<72$ hours, kept $<24$ h at $\mathrm{PCl}$ centre

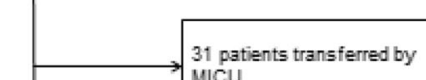
MICU

490 patients eligible for SCA-Alp admitted $<72 \mathrm{~h}$ in remote hospital, same-day round trip to and back from $\mathrm{PCl}$ centre)

Fig. 3 Flow charts of patients with a STEMI and b NSTEMI. ED: emergency department; NSTEMI: non-ST-segment elevation myocardial infarction; STEMI: ST-segment elevation myocardial infarction

\section{Results}

During the study period, 1172 patients with STEMI were treated in the Annecy PCI centre. Of these, 602 patients were transferred immediately (via MICU) from the emergency department at a remote hospital to the PCI centre $(n=225)$ or arrived after initial treatment in a MICU (from home) from a remote area $(n=377)$. Just over half $(54.0 \%)$ were treated with thrombolysis and $36.9 \%$ were admitted for primary PCI. One hundred and one of these patients were returned to their remote hospital using the SCA-Alp protocol within $48 \mathrm{~h}$ (Fig. 3a).

During the same period, 1968 patients with an initial diagnosis of NSTEMI were transferred from a remote hospital to the Annecy PCI centre, of which 867 were transferred using the SCA-Alp protocol and transferred back within $12 \mathrm{~h}$. A total of 490 patients initially stayed $<72 \mathrm{~h}$ in the remote hospital before transfer to the PCI centre and were transferred back using the SCA-Alp protocol within $12 \mathrm{~h}$ (Fig. 3b) (198 patients were transferred within $24 \mathrm{~h}, 168$ between 24 and $48 \mathrm{~h}$, and 124 between 48 and $72 \mathrm{~h}$ ).

Patient baseline characteristics, initial management, and angiographic characteristics are detailed in Tables 2 and 3. All patients were treated with a $\mathrm{P}_{2} \mathrm{Y}_{12}$ inhibitor before arrival at the cath-lab. Access was radial for most patients (94.6\%).

Ten of the 43 patients with STEMI admitted for an emergency angiogram and without previous fibrinolysis did not undergo PCI: four of these patients had a very narrow infarct-related artery (three had a final TIMI flow of 0 and one had a final TIMI flow of 2) and six had an initial TIMI flow of 3 and a non-significant lesion and/or the artery was too small to be dilated. Table 4 shows the initial TIMI flow distribution of the 43 patients admitted for an emergency angiogram without previous fibrinolysis and the final TIMI flow of the 82 patients treated with PCI (33 primary PCI, 20 rescue PCI after failed thrombolysis, and 29 treated with delayed PCI after successful thrombolysis).

Most patients with STEMI (90/101, 89.1\%) or NSTEMI $(467 / 490,95.3 \%)$ were transferred from or to the four main remote hospitals with an ICU. The mean maximum troponin concentration among NSTEMI patients was $1.69 \pm 7.8 \mu \mathrm{mol} / \mathrm{L}$ and the overall mean length of hospitalization in the remote hospital was $5.0 \pm 3.2$ days. 
Table 2 Patient baseline characteristics

\begin{tabular}{lll}
\hline & STEMI $(n=101)$ & NSTEMI $(n=490)$ \\
\hline Age, years & $56 \pm 14$ & $65 \pm 13$ \\
Men & $84(83.2)$ & $357(72.9)$ \\
Medical history & & \\
$\quad$ Hypertension & $27(26.7)$ & $225(45.9)$ \\
Diabetes mellitus & $12(11.9)$ & $89(18.2)$ \\
Smoking (current or past) & $53(52.5)$ & $162(33.1)$ \\
Dyslipidaemia & $20(19.8)$ & $156(31.8)$ \\
Peripheral artery disease & $1(1.0)$ & $14(2.9)$ \\
$\quad$ Stroke & $2(2.0)$ & $14(2.9)$ \\
Previous coronary artery disease & & $70(14.3)$ \\
PCI & $7(6.9)$ & $8(1.6)$ \\
CABG & $1(1.0)$ & $47(9.6)$ \\
Myocardial infarction & $9(8.9)$ & \\
Initial clinical presentation & & \\
SBP at admission, mmHg & $147.5 \pm 31.8$ & \\
Anterior myocardial infarction & $36(35.6)$ & \\
Lateral myocardial infarction & $9(8.9)$ & \\
Inferior myocardial infarction & $56(55.4)$ & \\
\hline
\end{tabular}

Data presented as mean \pm SD or $n(\%)$

CABG coronary artery bypass graft, NSTEMI non-ST-segment elevation myocardial infarction, $P C l$ percutaneous coronary intervention, $S B P$ systolic blood pressure, STEMI ST-segment elevation myocardial infarction

\section{Outcomes}

No deaths or other major events were reported during transportation; and no deaths occurred during the $48 \mathrm{~h}$ after transfer to the remote hospital. Two of 591 patients $(0.3 \%$ [95\% confidence interval $0.1-$ $1.4 \%]$ ) had to be transferred back to the PCI centre for repeat coronary angiography within 2 days of their primary PCI (Table 5). The first was a 36-year-old man admitted with anterior STEMI. Treatment with clopidogrel, aspirin, and bivalirudin was started before arrival at the cath-lab. The emergency coronary angiogram showed an occlusion with TIMI 0 flow of the left anterior descending artery. After thrombus aspiration, TIMI 3 flow was restored and the lesion was not significant. The patient was not stented and bivalirudin treatment was switched to low-molecular-weight heparin $2 \mathrm{~h}$ after the procedure. The patient was transferred to a remote hospital the following day, but experienced chest pain with ST-segment elevation $48 \mathrm{~h}$ after admission. He was immediately transferred in a MICU for an emergency coronary angiogram, which showed reocclusion of the infarct-related artery. Treatment with a glycoprotein IIb/IIIa inhibitor was administered in the cath-lab and a stent was implanted. The patient was event free at 6-month follow-up.
The second case was a 74-year-old man who was admitted to a remote hospital with NSTEMI and was treated with clopidogrel, aspirin, and lowmolecular-weight heparin. He was transferred according to the SCA-Alp protocol to the PCI centre $48 \mathrm{~h}$ after admission. A $70 \%$ stenosis was diagnosed in the mid left descending artery and a stent was implanted with a good result. He was transferred back to the remote hospital $4 \mathrm{~h}$ after PCI. He suffered an anterior STEMI $24 \mathrm{~h}$ after his return and was immediately transferred via MICU for an emergency coronary angiogram, which showed a stent thrombosis. This was treated with a glycoprotein IIb/ IIIa inhibitor and aspiration, and another stent was implanted downstream due to a possible occlusive dissection. The patient was event free at 6-month follow-up.

One patient experienced a radial haematoma that required surgical intervention the day after transfer to the remote hospital. One patient - who was receiving a glycoprotein IIb/IIIa inhibitor after the coronary angiogram - experienced a cerebral haematoma a few hours after his return to the remote hospital, but did not require surgical intervention and had no neurological disability. One patient had a STEMI due to a stent thrombosis 8 days after PCI, requiring emergency primary PCI.

\section{Discussion}

This retrospective study shows the feasibility of a protocol for early return to a non-interventional hospital after PCI for selected intermediate-risk patients with an ACS. No adverse events occurred during transportation without doctors or nurses on board during return transfer 24-48 h after PCI of patients with STEMI or for same-day round trips for patients within 24-72 h of NSTEMI. No deaths were reported and only two of 591 patients needed to be transferred back to the PCI centre within $48 \mathrm{~h}$ (in a MICU) for another PCI due to stent thrombosis. The SCA-Alp approach frees up beds in PCI centres, which are in increasing demand. Performing these transfers without doctors or nurses on board allows a more streamlined use of medical facilities, but requires a well-organized system with well-targeted patients, shared protocols and trained staff, as followed in our SCA-Alp protocol.

Comparison of our results with previous reports on early return transfers is difficult due to the heterogeneity in the risk level of ACS patients. Some studies have included high-risk patients with acute STEMI [4, 6, 7], while others have included lower-risk patients with NSTEMI $>72 \mathrm{~h}$ previously or unstable angina $[8,9]$. Also, some transfers were performed with doctors or 
Table 3 Initial treatment and angiographic characteristics

\begin{tabular}{|c|c|c|}
\hline & STEMI $(n=101)$ & NSTEMI $(n=490)$ \\
\hline \multicolumn{3}{|l|}{ Initial management } \\
\hline Primary MICU involvement & $79(78.2)$ & - \\
\hline Initial remote ED admission and immediate MICU transfer ${ }^{a}$ & $22(21.8)$ & - \\
\hline \multicolumn{3}{|l|}{ Medication before arrival in the cath-lab } \\
\hline Aspirin & $95(94.1)$ & $473(96.5)$ \\
\hline Clopidogrel & $63(62.4)$ & $310(63.3)$ \\
\hline Prasugrel & $14(13.9)$ & $10(2.0)$ \\
\hline Ticagrelor & $24(23.8)$ & $170(34.7)$ \\
\hline Unfractionated heparin & $15(14.9)$ & $191(39.0)$ \\
\hline Low-molecular-weight heparin & $71(70.3)$ & $292(59.6)$ \\
\hline Bivalirudin & $15(14.9)$ & $7(1.4)$ \\
\hline GP Ilb/llla inhibitor & $30(29.7)$ & $98(20.0)$ \\
\hline \multicolumn{3}{|l|}{ Interventional characteristics } \\
\hline \multicolumn{3}{|l|}{ Characteristics of CAD } \\
\hline Single-vessel disease & $69(68.3)$ & $258(52.7)$ \\
\hline Two-vessel disease & $25(24.8)$ & $119(24.3)$ \\
\hline Three-vessel disease & $7(6.9)$ & $57(11.6)$ \\
\hline No significant CAD & 0 & $56(11.4)$ \\
\hline Emergency primary coronary angiogram & $43(42.6)$ & \\
\hline (Primary) $\mathrm{PCl}$ & $33 / 43(76.7)$ & 274/490 (55.9) \\
\hline Fibrinolysis & $58(57.4)$ & \\
\hline Rescue coronary angiogram after fibrinolysis & $27(26.7)$ & \\
\hline Rescue PCl after fibrinolysis & 20/27 (74.1) & \\
\hline Delayed coronary angiogram after fibrinolysis & $31(30.7)$ & \\
\hline Delayed PCl after fibrinolysis & 29/31 (93.5) & \\
\hline Delayed bypass & $2(2.0)$ & $26(5.3)$ \\
\hline Medical treatment only (no PCI or CABG) & $17(16.8)$ & $190(38.8)$ \\
\hline Stent implantation & $75(74.3)$ & $250(51.0)$ \\
\hline Balloon only (no stent) & $7(6.9)$ & $24(4.9)$ \\
\hline
\end{tabular}

Data presented as $n(\%), n / N(\%)$, or mean $\pm S D$

CABG coronary artery bypass graft, CAD coronary artery disease, ED emergency department, GP glycoprotein, MICU mobile intensive care unit, NSTEMI non-ST segment elevation myocardial infarction, $P C I$ percutaneous coronary intervention, SD standard deviation, STEMI ST segment elevation myocardial infarction ${ }^{a}$ Patients who arrived at the remote hospital using their own transport

Table 4 Angiographic TIMl scores for patients with STEMI

\begin{tabular}{lll}
\hline TIMl score & Initial $^{\mathrm{a}}(n=43)$ & Final $^{\mathrm{b}}(n=82)$ \\
\hline 0 & $28(65.1)$ & $3(3.7)$ \\
1 & $6(14.0)$ & 0 \\
2 & 0 & $1(1.2)$ \\
3 & $9(20.9)$ & $78(95.1)$ \\
\hline
\end{tabular}

Data presented as $n(\%)$

$\mathrm{PCl}$ percutaneous coronary intervention, STEMI ST-segment elevation myocardial infarction, TIMI Thrombolysis In Myocardial Infarction a Only for those who underwent primary PCI

${ }^{\mathrm{b}}$ For primary, rescue, or delayed $\mathrm{PCl}$ with effective intervention paramedics on board and others without. However, our results are concordant with these reports regarding the risk of stent thrombosis $(0-2.2 \%)$ and in-hospital death (0-3.2\%) [6-9].

As MICUs are few in number and expensive, we hypothesised that many high-risk patients might be classified as being at intermediate risk for inter-hospital transfer, and hence be suitable for SCA-Alp transfer. We can define high-risk patients as those with acute STEMI, complicated patients, and those who have had an uncomplicated STEMI or NSTEMI within the last $24 \mathrm{~h}$. Such patients require MICU transportation. Low-risk patients are 
Table 5 Clinical outcomes

\begin{tabular}{lll}
\hline & STEMI $(n=101)$ & NSTEMI $(n=490)$ \\
\hline Primary endpoints & 0 & 0 \\
Death (in the first $48 \mathrm{~h}$ post $\mathrm{PCl})$ & $1(1.0)$ & $1(0.2)$ \\
Retransfer to $\mathrm{PCl}$ centre for second emergency coronary angiogram $\left(<48 \mathrm{~h}\right.$ after the cath-lab) ${ }^{\mathrm{a}}$ & 0 & 0 \\
Secondary endpoints & $1(1.0)$ & 0 \\
Stroke & 0 & $1(0.2)$ \\
Major haematoma at the puncture site & 0 & $1(0.2)$ \\
Major bleeding complication & & 0 \\
Stent thrombosis $>48 \mathrm{~h}$ after $\mathrm{PCl}$ & &
\end{tabular}

Data presented as $n(\%)$

NSTEMI non-ST-segment elevation myocardial infarction, $\mathrm{PCl}$ percutaneous coronary intervention, STEMI ST-segment elevation myocardial infarction

${ }^{a}$ For suspicion of stent thrombosis or dilated artery reocclusion in the absence of a stent placement or dilated artery reocclusion in the absence of a stent

those with uncomplicated STEMI $>48 \mathrm{~h}$ ago or uncomplicated NSTEMI $>72 \mathrm{~h}$ ago. Intermediate-risk patients can therefore be defined as those with uncomplicated STEMI within the last $24-48 \mathrm{~h}$ or uncomplicated NSTEMI within the last $24-72 \mathrm{~h}$. The results of our study suggest that these patients can be safely transferred using a protocol such as SCA-Alp. The risk level of patients with uncomplicated NSTEMI within the last $24 \mathrm{~h}$ is unclear, but they may be considered at intermediate risk, as Bawejski et al. [5] reported no complications requiring medical intervention among 93 such patients transported with doctors or nurses on board. Moreover, despite our protocol criteria, 198 patients with NSTEMI were transferred within $24 \mathrm{~h}$ by SCA-Alp in our study, without any reported complications. Of course, risk levels may be better defined using scoring systems such as the Global Registry of Acute Coronary Events (GRACE) [16]. This may provide a better risk estimation, and the use of GRACE could be examined in a future study.

Our approach addresses an important public health issue as most of our patients came from remote areas (602/1172 [51.3\%] STEMI and 1968/2554 [77.1\%] NSTEMI), and there are not enough doctors to perform such MICU transfers. The SCA-Alp protocol is based on a strong network and shared practices regarding cardiovascular diseases in our region.

Reocclusion occurred in two of our patients, one of whom was treated with bivalirudin, which increases the risk of acute stent thrombosis $[17,18]$. Our inclusion period was also transitional in terms of antiplatelet therapy, and perhaps these stent thromboses would have been avoided with the use of the newest $\mathrm{P} \mathrm{Y}_{12}$ inhibitors, ticagrelor and prasugrel. Indeed, PCI techniques continue to evolve and the intervention is becoming safer, allowing earlier return of patients, with almost systematic use of radial access for the coronary angiogram ( $>94 \%$ ), which is known to reduce bleeding risk [19].

\section{Limitations}

This retrospective observational study is subject to the usual limitations of such analyses. Some events may not have been reported by the remote hospitals, and the reporting of complications was limited to patients who had a successful PCI (with the exception of the primary endpoints, which were known for all patients). It is possible that some events (e.g. stent thrombosis in an elderly patient) did not result in their transfer back to the PCI centre. However, the examination of remote hospital medical records of patients who had undergone PCI did not reveal any such unreported events. In view of the study aims, we focused on outcomes that would have proven the failure of early return. We acknowledge that other complications, such as stroke or bleeding events, are similarly treated in remote hospitals. Patients were not under continuous rhythm monitoring during transportation, so we cannot exclude the occurrence of minor complications that did not require medical intervention [5]. As a retrospective study, some patients who would have been eligible for the SCA-Alp protocol were not included for reasons that remain unknown. In addition, we cannot confirm that the SCA-Alp protocol was followed precisely. For example, 198 patients with NSTEMI $<24 \mathrm{~h}$ previously were included, who were not eligible according to the protocol.

\section{Conclusions}

The results of this retrospective observational study suggest that the early transfer of intermediate-risk ACS patients between PCI centres and remote hospitals without doctors, paramedics, or nurses on board - is feasible, and is associated with low event rates. 


\section{Appendix}

Investigators and remote hospital destinations

\begin{tabular}{llll}
\hline & Investigator & STEMl & NSTEMI (n=490) \\
\hline Annemasse hospital & Claire Vallenet & $35(34.7)$ & $200(40.8)$ \\
Sallanches hospital & Frederic Champly & $22(21.8)$ & $83(16.9)$ \\
Thonon hospital & Guillaume Peribois & $21(20.8)$ & $126(25.7)$ \\
Saint Julien hospital & Cedric Lutz & $12(11.9)$ & $58(11.8)$ \\
Albertville hospital & Marc Haesevoets & $5(5.0)$ & $5(1.0)$ \\
Chambery hospital & Pascal Usseglio & $6(5.9)$ & $8(1.6)$ \\
Annemasse clinic & Christian Curvat & 0 & $7(1.4)$ \\
Argonay clinic (Annecy) & Dominique Savary & 0 & $2(0.4)$ \\
Rumilly hospital & Dominique Savary & 0 & $1(0.2)$ \\
\hline
\end{tabular}

Data are presented as $n$ (\%)

NSTEMI non-ST-segment elevation myocardial infarction, STEMI ST-segment elevation myocardial infarction

\section{Abbreviations}

ACS: Acute coronary syndromes; ED: Emergency department; ICU: Intensive care unit; ICU: Intensive care unit; MICU: Mobile intensive care unit; NSTEMI: Non-ST-segment elevation myocardial infarction; PCl: Percutaneous coronary intervention; PCl: Percutaneous coronary intervention; RENAU: REseau Nord Alpin des Urgences; RESURCOR: RESeau des URgences CORonaires; SD: Standard deviation; STEMI: ST-segment elevation myocardial infarction; TIMI: Thrombolysis In Myocardial Infarction

\section{Acknowledgements}

The authors would like to thank RENAU Investigators (Emergency Departments MD):

Frederic Champly (Hôpital de Sallanches), Christian Curvat (Hôpital privé Haute Savoie nord), Marc Haesevoets (Hôpital d'Albertville), Guillaume Peribois (Hôpital de Thonon), Dominique Savary (Hôpital d'Annecy), Pascal Usseglio (Hôpital de Chambery), Claire Vallenet (Hôpital d'Annemasse). We also like to thank Jean-Pierre Perfus (MD) that set up this protocol, Blandine Lafitte for data collection, Hende Madiot for data management and Cecile Ricard for statistical analysis. Editorial assistance was provided by MedLink Healthcare Communications Limited.

\section{Funding}

This study was partly funded by the French Ministry of Health (PREPS 2014 14-0040). The research unit of the hospital of Annecy receive a grant from Terumo, Abbott, St Jude Medical, Boston, Medtronic and Biotronik. The funding bodies had no involvement in the design of the study; in the collection, analysis, and interpretation of data; or in writing the manuscript.

\section{Availability of data and materials}

The datasets used and/or analysed during the current study are available from the corresponding author on reasonable request.

\section{Authors' contributions}

SC, MR and LB enrolled patients, analysed and interpreted the data and wrote the first draft of the manuscript. CV, PF, FC, PB, GP, VS, CL, LM, DS, FXA, enrolled patients. All authors read and approved the final manuscript.

\section{Ethics approval and consent to participate}

The study was conducted according to the World Medical Association ethical principles for medical research involving human subjects. Patient consent was not required, according to the hospital policy on use of the database.

\section{Consent for publication}

Not applicable.

\section{Competing interests}

LB: research grants from Novartis, Astra-Zeneca, Lilly, Sanofi, Correvio, Medtronic, Biotronik, Abbott, Boston, Celonova, Terumo and St Jude.

\section{Publisher's Note}

Springer Nature remains neutral with regard to jurisdictional claims in published maps and institutional affiliations.

\section{Author details}

'Department of Cardiology and Emergency Department, Centre Hospitalier Alpes-Leman, Annemasse, France. ${ }^{2}$ Department of Cardiology and Emergency Department, Centre Hospitalier Annecy-Genevois, Annecy, France. ${ }^{3}$ Department of Cardiology and Emergency Department, Centre Hospitalier de Sallanches, Sallanches, France. ${ }^{4}$ Department of Cardiology and Emergency Department, Centre Hospitalier de Thonon, Thonon, France.

Received: 26 February 2018 Accepted: 29 April 2019

Published online: 28 October 2019

\section{References}

1. Task Force on the management of ST-segment elevation acute myocardial infarction of the European Society of Cardiology, Steg PG, James SK, Atar D, Badano LP, Blomstrom-Lundqvist C, et al. ESC guidelines for the management of acute myocardial infarction in patients presenting with STsegment elevation. Eur Heart J. 2012;33:2569-619.

2. Roffi M, Patrono C, Collet JP, Mueller C, Valgimigli M, Andreotti F, et al. 2015 ESC guidelines for the management of acute coronary syndromes in patients presenting without persistent ST-segment elevation: task force for the Management of Acute Coronary Syndromes in patients presenting without persistent ST-segment elevation of the European Society of Cardiology (ESC). Eur Heart J. 2016;37:267-315.

3. Adnet F, Lapostolle F. International EMS systems: France. Resuscitation. 2004; 63:7-9.

4. Paul E, Konan B, Guitteny S, Chatoui A, Joye F, Hulard G. Acute coronary syndrome: an analyse of complications during interhospital transports to interventional coronary departments. Presse Med. 2008;37:1366-70.

5. Bawejski S, Trebouet E, Boiffard E. Analysis of cardiovascular complications occurring during inter-hospital transfers of patients with uncomplicated non-ST elevation myocardial infarction. Ann Cardiol Angeiol (Paris). 2014;63: 228-34.

6. Margheri M, Meucci F, Falai M, Comeglio M, Giglioli C, Chechi T, et al. Transferring patients for direct coronary angioplasty: a retrospective analysis of 135 unselected patients with acute myocardial infarction. Ital Heart J. 2001;2:921-6

7. Estevez-Loureiro R, Calvino-Santos R, Vazquez JM, Barge-Caballero E, Salgado-Fernandez J, Pineiro $M$, et al. Safety and feasibility of returning 
patients early to their originating centers after transfer for primary percutaneous coronary intervention. Rev Esp Cardiol. 2009;62:1356-64

8. Do DH, Dalery K, Gervais A, Harvey R, Lepage S, Maltais A, et al. Same-day transfer of patients with unstable angina and non-ST segment elevation myocardial infarction back to their referring hospital after angioplasty. Can J Cardiol. 2006;22:405-9.

9. Andersen JG, Klow NE, Johansen O. Safe and feasible immediate retransfer of patients to the referring hospital after acute coronary angiography and percutaneous coronary angioplasty for patients with acute coronary syndrome. Eur Heart J Acute Cardiovasc Care. 2013;2:256-61.

10. Comparateur de territoire. Département de La Haute-Savoie (74). Accessed 25 May 2016. https://www.insee.fr/fr/statistiques/1405599?geo=DEP-74.

11. Belle L, Labarere J, Fourny M, Cambou JP, Danchin N. Variations in the management of patients with acute myocardial infarction in alpine hospitals compared to other French hospitals. Secondary analysis of the USIC 2000 study data. Ann Cardiol Angeiol (Paris). 2005;54:310-6.

12. Debaty G, Belle L, Labarere J, Fourny M, Torres JP, Savary D, et al. Evolution of strategies of revascularisation in acute coronary syndromes with ST elevation. Analysis of the data of RESURCOR. Arch Mal Coeur Vaiss. 2007;100: 105-11.

13. Fourny M, Belle L, Labarere J, Senee D, Savary D, Debaty G, et al. Analysis of the accuracy of a coronary syndrome registerArch Mal Coeur Vaiss. 2006;99: 798-803.

14. Fourny M, Lucas AS, Belle L, Debaty G, Casez P, Bouvaist H, et al. Inappropriate dispatcher decision for emergency medical service users with acute myocardial infarction. Am J Emerg Med. 2011:29:37-42.

15. Yayehd K, Ricard C, Ageron FX, Buscaglia L, Savary D, Audema B, et al. Role of primary care physicians in treating patients with ST-segment elevation myocardial infarction located in remote areas (from the REseau Nord-Alpin des Urgences [RENAU], network). Eur Heart J Acute Cardiovasc Care. 2015;4: 41-50.

16. Granger CB, Goldberg RJ, Dabbous O, Pieper KS, Eagle KA, Cannon CP, et al. Predictors of hospital mortality in the global registry of acute coronary events. Arch Intern Med. 2003;163:2345-53.

17. Steg PG, van 't Hof A, Hamm CW, Clemmensen P, Lapostolle F, Coste P, et al. Bivalirudin started during emergency transport for primary PCI. N Engl J Med. 2013:369:2207-17.

18. Stone GW, Witzenbichler B, Guagliumi G, Peruga JZ, Brodie BR, Dudek D, et al. Bivalirudin during primary $\mathrm{PCl}$ in acute myocardial infarction. N Engl J Med. 2008;358:2218-30.

19. Jolly SS, Amlani S, Hamon M, Yusuf S, Mehta SR. Radial versus femoral access for coronary angiography or intervention and the impact on major bleeding and ischemic events: a systematic review and meta-analysis of randomized trials. Am Heart J. 2009:157:132-40.

Ready to submit your research? Choose BMC and benefit from:

- fast, convenient online submission

- thorough peer review by experienced researchers in your field

- rapid publication on acceptance

- support for research data, including large and complex data types

- gold Open Access which fosters wider collaboration and increased citations

- maximum visibility for your research: over $100 \mathrm{M}$ website views per year

At $\mathrm{BMC}$, research is always in progress.

Learn more biomedcentral.com/submissions 